\title{
Phytochemical Investigation and Antioxidant Activity of Leaf Extract of Withania somnifera from Konso, South Ethiopia
}

\author{
TESFAYE TEBEKA SIMUR \\ Department of Chemistry, Arba Minch University, Arba Minch, Ethiopia. \\ ${ }^{*}$ Correspondence author E-mail: tesffish41@gmail.com \\ http://dx.doi.org/10.13005/ojc/3404016
}

(Received: July 02, 2017; Accepted: June 11, 2018)

\begin{abstract}
Withania somnifera is endemic to Ethiopia where its leaf and root is traditionally used for the treatment of malaria in south Ethiopia. The main purpose of this study was to investigate phytochemicals and antioxidant activity of the leaf extract of Withania somnifera. The anti-oxidant potential and total antioxidant potential was determined by using reducing power determination method and phosphomolybdate method respectively. As per the phytochemical tests, the methanol extract revealed that presence of tannins, phenolics, flavonoids, saponins and, alkaloids while all are absent in hexane extract. The antioxidant capacity of methanol, acetone and hexane leaf extracts of Withania somnifera were found to be $494.088 \pm 0.230,104.190 \pm 0.020$ and $3.413 \pm 0.023 \mathrm{mg}$ of ascorbic acid per $10 \mathrm{mg}$ of dry weight of antioxidant in the reducing power, respectively and it's total antioxidant capacity of these extracts were $45.41 \pm 0.018,8.70 \pm 0.004$ and $0.38 \pm 0.002 \mathrm{mg}$ of ascorbic acid per $10 \mathrm{mg}$ of dry weight of the crude extract. Thus, the results of the present investigation infer that this plant extracts possess potent antioxidant. Therefore it is strongly recommended to isolate the antioxidant components.
\end{abstract}

Keywords: Withania somnifera, Antioxidant potential, FRAP assay, Total antioxidant capacity.

\section{INTRODUCTION}

Nowadays free radical species are the major causes of degenerative diseases. Degenerative diseases such as cataracts, immune system decline, brain dysfunction, high blood pressure and many more are caused by free radical-induced chain reaction ${ }^{1,2,3}$ Besides to this, shortage of fruits and vegetable consumptions are also the causes of these diseases. ${ }^{4}$
Recent studies conducted on free radical reveal that, there is a huge surge of interest in studying the importance of free radicals in biological system, due to their impact on human health and disease control system as both deleterious and beneficial effect to the living systems. ${ }^{5}$

The source of free radical can be internal and external sources. At low concentration these, reactive species have important effects

This is an Open Access article licensed under a Creative Commons Attribution-Non Commercial-Share Alike 4.0 International License (https://creativecommons.org/licenses/by-nc-sa/4.0/), which permits unrestricted Non Commercial use, distribution and reproduction in any medium, provided the original work is properly cited. 
and involve in different biological functions. ${ }^{6,7}$ The harmful effect of free radicals causing potential biological damage is termed oxidative stress and nitrosative stress. This occurs in biological systems when there is an overproduction of ROS/RNS on one side and a deficiency of enzymatic and non-enzymatic antioxidants on the other. To overcome overproduction of free radicals during disease conditions external supply of antioxidants is required to balance the negative consequences of free radicals. ${ }^{8,9}$

Antioxidants are capable of stabilizing, or deactivating, free radicals thereby safeguarding cells from oxidative damage. ${ }^{10}$ Antioxidants are compounds that detoxify ROS and prevent their damage through; preventative, repair, physical defenses mechanism defenses. ${ }^{11}$

From previous studies and literature report, natural compounds were reported to have stronger antioxidant activity. ${ }^{12}$ With respect to antioxidant activity, plants and their products have medicinal benefits which play a significant role in day to day live activities. There are lots of diseases that human can encounter during their daily lives and fortunately the environment always provide many natural compound that can help prevent such many diseases with the help of the scientist that explore their knowledge in examining the wonders of nature to provide natural medicine.

There has been a huge surge of interest in natural antioxidants primarily due to their capacity to trap free radicals and thus shield the body from oxidative damage. ${ }^{14}$ Specifically flavonoid and phenolic compounds are dominate among secondary metabolites that are obtained from plant metabolism. Such information is dearth on most indigenous Ethiopian herbs and this limits their use internationally as preservatives and functional ingredients. It is therefore necessary to evaluate the antioxidant properties of the indigenous species to diversify their use in different forms that contain active ingredients that promote health and reduce the risk of disease.

The majority of the populations in developing countries rely on herbal preparation to help enhance health. The necessity to resist numerous health problems on one hand, and the insufficient health care coverage on the other, plays a critical role in the observed utilization of more accessible and affordable medicinal plants by the majority of Ethiopians. ${ }^{13,14}$

Withania somnifera is endemic to Ethiopia where its leaf and root is traditionally used for the treatment of malaria in south Ethiopia. ${ }^{15}$ Withania somnifera (L.) is a shrub usually under I $\mathrm{m}$ in height. Leaves, stems, and fruits are tomentose. Flowers are greenish and red fruit. Withania somnifera is a commonly known medicinal plant in India. ${ }^{16}$ The Withania somnifera, belonging to the family Solanaceae, is also known by its local names as 'Chemotita in konso, Gisewa (Amharic), in Ethiopia and ashwagandha' in India. ${ }^{17} \mathrm{~A}$ research conducted by Fassil and co-worker (1999) showed that $W$. somnifera is used for the treatment of different ailments. ${ }^{18}$ Research notes that, the plant is traditionally use to treat malaria in Ethiopia. ${ }^{19}$ In addition to this, both in-vivo and in-vitro research revealed that, the root and leaf of this indigenous plant showed antimalarial activities. ${ }^{15}$ But there is no similar report on the antioxidant potential of the leaf of $W$. somnifera plant specifically grown in Ethiopia. Therefore, the main purpose of this work is to investigate the antioxidant potential of the leaf of this plant using a variety of standard procedures. Indeed antioxidant activity could influence by geographical origin, cultivar and harvest, storage time.$^{20}$

Systematic phytochmical screening is required to identify the major classes of bioactive constituents in the extractants of Withina samifera leaves for understanding secondary metabolites obtained as a result of plant metabolism. To the best our knowledge there is also no reported date on preliminary phytochemical screening of Withina samifera leaf extract in Ethiopia. Therefore, the purpose of this work is also to investigate the bioactive components of this plant following standard procedures.

\section{MATERIALS AND METHODS}

Chemicals: in this study, analytical graded chemicals were used. Ammonium molybdate teterahydrate(Avonchem,UK), Ascobricacid (Unichem, India), potassium ferricyanide 
(Thecno Pharmchem., India), Trichloroacetic acid (JHD, China), Sodium dihydrogen phosphate and Disodium hydrogen phosphate were from (Fine- Chem ,India).

Apparatus: Absorbance reading was taken from single Beam UV- Visible (Vu-65) spectrophotometer and recorded it in a table for further analysis.

\section{Sample collection and extraction procedure}

Relevant information regarding the traditional use of the plant, its local names, part(s) used, were obtained from three traditional healers from study site before collecting the specimen. Based on the information obtained, leaves samples of indigenous Withania somnifera plant was collected from Konso (south, Ethiopia) and authenticated by a botanist in the Department of Biology, Arba Minch University, Ethiopia.

The leaf was dried at room temperature and then it was ground with electrical grinder. Ground dry plant materials $(50 \mathrm{~g})$ were weighed into three different Erlenmeyer flasks and dissolved in 250 $\mathrm{mL}$ of methanol, acetone and hexane, completely covered with aluminum foil, and occasionally shaken at 25 degree Celsius for 48 hours. The three extracts were filtered. The residue was dissolved in $250 \mathrm{~mL}$ of the respective solvents in the same procedure above and the filtrates were evaporated by rotary evaporator to remove the solvent in the sample solution. The mass of the individual crude extract was weighed: $10.65 \mathrm{~g}, 2.58 \mathrm{~g}, 0.47 \mathrm{~g}$ of methanol, acetone and hexane extract, respectively. And then the extracts were suspended with $50 \mathrm{~mL}$ distil water for further analysis. Chlorophyll and carotenoids strongly absorbs light in both the $400 \mathrm{~nm}$ and the $600 \mathrm{~nm}$ region and may influence the absorbance of samples with plant extract. ${ }^{21}$ Therefore, the chlorophyll was removed from the plant extract by charcoal.

\section{Preliminary Phytochemical screening}

The qualitative screenings of secondary metabolites were done on the crude extract of methanol, acetone and hexane extracts. The presence of secondary metabolites were examined following standard procedures with minor modifications. ${ }^{22}$
Alkaloids test: the crude extract of methanol, acetone and hexane were mixed with dilute $\mathrm{HCl}$ and filtered respectively and then, to the acidic solution, Wagner's reagent was added. Brown precipitate is a positive test for the presence of alkaloids. Saponins: one milliliter of the extracts was swirled with tow milliliter of water. The formation of foam indicates saponins. Phenols test: four drops of ferric chloride solution and one milliliter extracts were added in a test tube. Bluish-black color is a positive test for phenols. Tannins test: one $\mathrm{mL}$ of filtrate and three drops of ferric chloride solution were mixed. A blackish precipitate indicates tannins. Flavonoids test: one milliliter of the sample was treated with ten drops of sodium hydroxide solution. At bingeing of the reaction, intense yellow color was observed and the yellow color was disappeared up on addition of $2 \mathrm{~mL} 10$ percent $\mathrm{HCl}$, indicates the presence of flavonoids.

Procedure for ferric reducing power determination

In this study, the reducing power of the extracts were evaluated based on the procedure as explained by Atawodi et al.,(2010) with minor modification. ${ }^{23} 2.5 \mathrm{~mL}(2-2.8 \mathrm{mg} / \mathrm{mL})$ of each crude extracts and sodium phosphate buffer $(2.5 \mathrm{~mL}, 0.2$ $\mathrm{M}, \mathrm{pH}$ 6.6) were mixed. $2.5 \mathrm{~mL}$ of $1.0 \%$ potassium ferricyanide was added. The solution was kept at $50^{\circ} \mathrm{C}$ for twenty minutes. $2.5 \mathrm{~mL}$ of $10 \% \mathrm{Cl}_{3} \mathrm{CCOOH}$ was added and centrifuged at $300 \mathrm{rpm}$ for $10 \mathrm{~min}$. five milliliter of the supernatant was diluted with $5.0 \mathrm{~mL}$ of water. $0.1 \mathrm{~mL}$ of $\mathrm{FeCl}_{3}$ was added. $2.6 \mathrm{mg} / \mathrm{mL}$ of methanol, acetone and hexane extracts were taken to determine the antioxidant power of the extracts in terms of ascorbic acid standard with the linear curve of ascorbic acid standard at $700 \mathrm{~nm}$.

\section{Procedure fortotal Antioxidant capacity determination: Phosphomolybdate assay}

In this study, Phosphomolybdate method was used to determine the total antioxidant capacity of the different solvent extracts and the method we were used is described by Umamaheswari et al., (2008) with minor modification. ${ }^{24}$ Three millileter of phosphomolybdate reagent and $300 \mu \mathrm{L}$ of the plant extracts were added in a test tube and then they were kept in water bath at ninety five degree Celsius for ninety minutes. At $695 \mathrm{~nm}$ the absorbance of the sample were taken against water as a reference solution. The total antioxidant capacities of the 
samples were determined using ascorbic acid in the range of $(50-500 \mathrm{ppm})$ at $2.6 \mathrm{mg} / \mathrm{mL}$ of the crude extracts.

\section{Statistical determination}

All the experimental data has been presented as Mean \pm Standard deviation. One way ANOVA with significance level set as $p \leq 0.05$ by applying Tukey's post hoc test was used to check the significance of the data (SPSS 20 software package (IBM Corporation,1989). Origin 7 software was used to draw graphs.

\section{RESULTS AND DISCUSSION}

\section{Extraction yield and photochemical investigation}

In this study, solvent extraction method is used. Previous studies showed that, liquid-liquid extraction technique is most commonly used method to draw valuable mixture of compounds. The difference in yield and its antioxidant potential of the extract is may be due to the difference in chemical behavior of antioxidant constituents and the solubility nature of the components being studied in the given solvent. ${ }^{25}$ The percentage yield and the corresponding antioxidant potential of different solvent extracts of Withania sominefera leaf are presented in Table 3. In this study, the highest yield was obtained in the methanol extract $(21.3 \%)$ while the lowest yield was in the hexane extract (0.944\%). The higher polar solvent has a greater extracting power for different extraction on medical plant extraction. Indeed, this type of result is reported previously elsewhere.

\section{Table 1: Results of phytochemical analyses of different solvent extracts of $W$. somnifera}

Types of
phytochemicals

\begin{tabular}{lccc}
\hline Tests & Hexane & Acetone & Methanol \\
Phenols & - & + & + \\
Flavonoids & - & + & + \\
Tannins & - & + & + \\
Saponins & - & - & + \\
Alkaloids & - & - & + \\
Cardic glycoside & - & - & + \\
\hline
\end{tabular}

Where_absent, and + present

\section{Phytochemical screening of extracts}

Qualitative screening was carried out on the three extracts to detect alkaloids, flavonoids and tannins, phenols, saponins and cardic glycoside according to literature report. As per the phytochemical tests, the extracts obtained from Withania somnifera leaf using methanol showed the presence of tannins, phenolics, flavonoids, saponins alkaloids and, cardic glycoside while the acetone extract showed positive result only for tannins, phenols and flavonoids and all are absent in hexane extract as shown in Table1. This is in agreement with earlier reported work of the leaves of withania somnifera phytochemicls. ${ }^{26}$

Phytochemicals are currently receiving increased attention due to their ability to act as a therapeutic agent, which make them as alternative medicine to treat different types of diseases. ${ }^{27}$ The tannins, phenolics, flavonoids, saponins and alkaloids detected in these extracts could implicate these classes of phytochemicals as important bioactive agents of the leaf parts of this plant and might be involved in the therapeutic action. Medical plant is of a huge advantage to the health of individuals and communities.

\section{Results of Ferric Reducing Antioxidant Power (FRAP) Determination}

The presence of antioxidants in the extracts results in reduction of $\mathrm{Fe}$ (III) to $\mathrm{Fe}$ (II) by donating an electron. The concentration of Fe (II) produced due to reduction up on addition of the plant extracts can be measured using UV-visible spectrophotometer at $700 \mathrm{~nm}$. The antioxidant potential of the leaf in this study was determined using ascorbic acid standard at different concentrations (50-500 ppm). A graph of absorbance versus concentration of ascorbic acid was drawn with the following equation $y=0.162+$ $0.529 x$ and linear regression coefficient $\left(R^{2}=0995\right)$ Fig. 1 and the values are presented in Table 2.

The reducing capacity of the test compound (extracts) showed us a significant indicator of its antioxidant potential. The antioxidant potential of methanol, acetone and hexane extracts of Withania somnifera leaf were found to be $494.088 \pm 0.230$, $104.190 \pm 0.020$ and $3.413 \pm 0.023 \mathrm{mg}$ of $\mathrm{AAE} / 10 \mathrm{mg}$ of dry weight of the extract, respectively. 
During the experimentation, it was observed that the intensity of Perls blue color formation is increased due to $\mathrm{Fe}\left[(\mathrm{CN})_{6}\right]^{3}$ to $\mathrm{Fe}\left[\left(\mathrm{CN}_{6}\right]^{2}\right.$ complex formation in presence of test sample implies that the sample is electron donor and therefore it has antioxidant behaviour. ${ }^{28,29}$

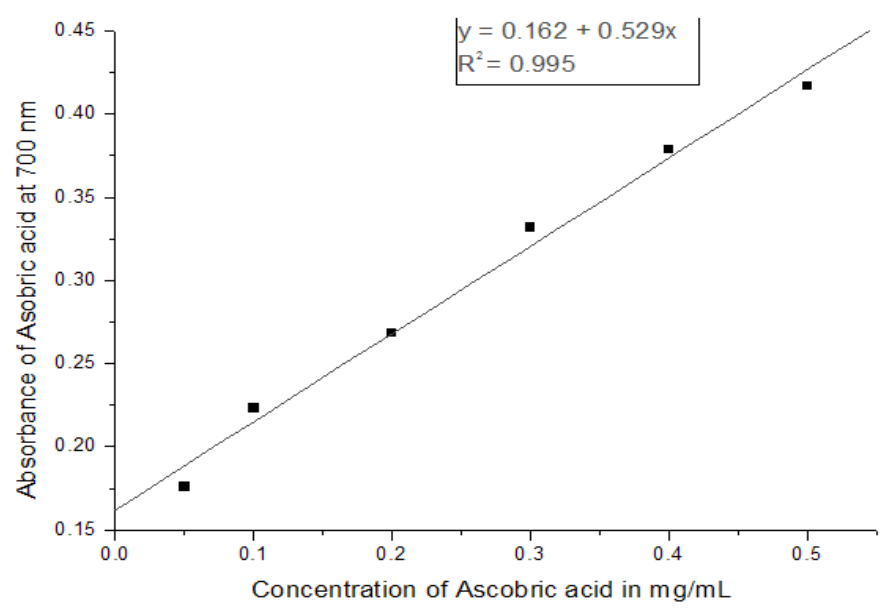

Fig. 1. Calibration curve of a series of standard solution of ascorbic acid in reducing power

Table 2: Antioxidant activities of Withania somnifera leaf extracts in FRAP assay

\begin{tabular}{|c|c|c|}
\hline $\begin{array}{l}\text { Extracts of Withania } \\
\text { somnifera }\end{array}$ & $\begin{array}{c}\text { AOAain terms } \\
\text { of AAEb/ } \\
10 \mathrm{mg} \mathrm{mg}\end{array}$ & $\begin{array}{r}\text { Percentage } \\
\text { yield weigh } \\
\text { of extract }\end{array}$ \\
\hline & & \\
\hline Acetone extract & $104.190 \pm 0.020 d$ & 5.16 \\
\hline Hexane extract & $3.413 \pm 0.023 e$ & 0.944 \\
\hline
\end{tabular}

The experimental data are presented in mean $\pm S D$ for three measurement analysis. $\mathrm{AOA}^{\mathrm{a}}$ is antioxidant potential, $A A E^{b}$ is ascorbic acid equivalent.
Table 3 showed the ferric reducing potential of different extracts of withania somnifera leaf. Hexane extract of withania somnifera leaf showed less degree of $\mathrm{Fe}^{3+}$ reduction than the methanolic extracts and lees reducing power than acetone extract of withania somnifera leaf. The higher the absorbance, the higher would be the reducing power. The general trend obtained in this study is as follows: MEWS >AEWS > HEWS. The higher reducing power of methanol extract is may be due to the presence of higher phytochemicals in the extract and hence related with the more dissolving ability of the solvent.

Table 3: Percent reducing power of different solvent extracts of Withania somnifera leaf

\begin{tabular}{cccc}
\hline & \multicolumn{3}{c}{ Percent reducing power in FRAP assay } \\
Concentration in $\mathrm{mg} / \mathrm{mL}$ & MEWS $^{\mathrm{a}}$ & AEWS $^{\mathrm{b}}$ & HEWS $^{\mathrm{c}}$ \\
\hline 2 & $96.94 \pm 0.049 \mathrm{a}$ & $96.79 \pm 0.005 \mathrm{a}$ & $90.50 \pm 0.130 \mathrm{a}$ \\
2.2 & $97.58 \pm 0.003 \mathrm{~b}$ & $97.51 \pm 0.009 \mathrm{~b}$ & $90.65 \pm 0.087 \mathrm{~b}$ \\
2.4 & $97.68 \pm 0.003 \mathrm{c}$ & $97.49 \pm 0.012 \mathrm{c}$ & $91.80 \pm 0.067 \mathrm{c}$ \\
2.6 & $97.97 \pm 0.053 \mathrm{~d}$ & $97.76 \pm 0.002 \mathrm{~d}$ & $95.39 \pm 0.074 \mathrm{~d}$ \\
2.8 & $98.03 \pm 0.039 \mathrm{e}$ & $97.99 \pm 0.024 \mathrm{e}$ & $97.43 \pm 0.020 \mathrm{e}$ \\
& & & \\
\hline
\end{tabular}

Mean \pm standard deviation of triplicate analysis. MEWSa is methanol extract of Withania somnifera leaf, AEWSb is acetone extract and HEWSc is hexane extract. 


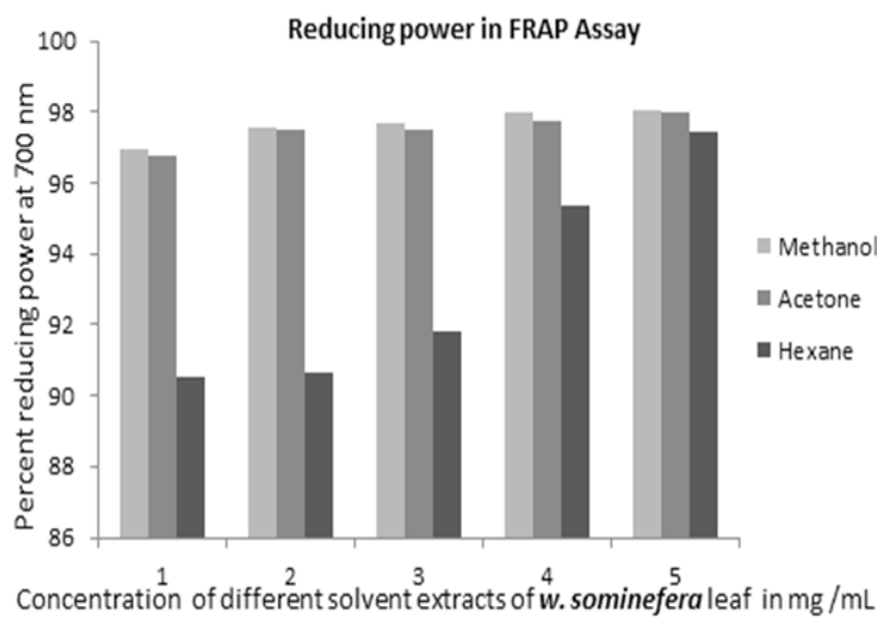

Fig. 2. Percent reducing power versus different solvent of extracts (in $\mathrm{mg} / \mathrm{mL}$ ) of Withania somnifera leaf in FRAP method

As can be seen from Fig. 2, an increase in percent reducing power of the extract would indicate an increase in the reducing capacity due to an increase in the formation of the Fe (II) complex. It was observed that, the reducing power increased as the extract concentration increased, indicating some polyphenolic compounds in sample extracts were electron donors. The result we obtained here is in agreement with previous studies and literature reports. ${ }^{30}$

\section{Total Antioxidant Capacity determination}

Total Antioxidant capacity (TAC) is the measure of the ability of substances extracted from food (plants or animals) to slow down oxidative stress. The antioxidant activity for the different extracts of Withania somnifera leaf was evaluated by using phosphomolybdate method. It determines the total antioxidant capacity. The method is usually used to determine the total antioxidant capacity of plant extracts. ${ }^{31}$ the basic principle of the assay is based on the reduction of $\mathrm{Mo}(\mathrm{VI})$ to $\mathrm{Mo}(\mathrm{V})$ in presence antioxidant components from the substance being studied.

Total antioxidant capacity of Withania somnifera leaf extracts is expressed in terms of ascorbic acid equivalents ( $\mathrm{mg}$ of AAE/10mg of dry weight of the crude extract). For the determination of total antioxidant capacity, ascorbic acid is used as a reference standard from which plant extracts with potential antioxidant activity are evaluated and its calibration curve is drawn with the following equation $y=0.11284+0.50641 x$ and linear regression coefficient $\left(R^{2}=091416\right)$ Fig. 3 and Table 4.

The extracts showed different range of total antioxidant capacity and this may be associated with the high amounts of polyphenol compounds extracted in the corresponding solvent in plant extracts. The methanolic extract of Withania somnifera leaf is highest total antioxidant capacity while the hexane extract of Withania somnifera leaf showed the least total antioxidant capacity. Thus this is an indication of different antioxidant capacity that may be due to different concentration of secondary metabolites in the extracts since it was extracted in different solvents.

From Table 4, the total antioxidant capacity of Withania somnifera leaf for methanol acetone and hexane extracts are $45.41 \pm 0.018,8.70 \pm 0.004$ and $0.38 \pm 0.002 \mathrm{mg} / 10 \mathrm{mg}$ of dry of weight of crude extract respectivelly. Thus the general order of their total antioxidant capacity of the extracts is methanol extract >acetone extract> hexane extract and the corresponding antioxidant capacity values has been presented in Table 4.

As can be seen from Fig. 4; as the concentration of the extract increases so does its antioxidant capacity. This may not be always the case sometimes it may act as pro-oxidant activity. The methanol extract showed a much higher activity than the other three extracts at low concentration, while the hexane extract showed a much lower 
activity. This order of activity is due to from polar methanol to non-polar hexane extract. This is due to the extracting ability of polar solvents over non-polar solvents and hence extracts polar phytochemicals. For the sake of observing the increment in absorbance with increasing concentration of samples, a graph of absorbance versus concentration was constructed as depicted in Fig. 4. Roopalath and co-workers reported that total antioxidant capacity is increases with the increase in concentration of sample. ${ }^{22}$ The sample we investigated in the present study would exhibit similar antioxidant effects.
Table 4: Total Antioxidant capacity of different solvent extracts of Withania somnifera leaf

\begin{tabular}{lc}
\hline Crude extract & $\begin{array}{c}\text { TOC }^{\mathrm{a}} \text { in terms of } \mathrm{mg} \\
\mathrm{AAE}^{\mathrm{b}} / 10 \mathrm{mg} \text { weight } \\
\text { of } \mathrm{CE}^{\mathrm{c}}\end{array}$ \\
\hline Methanol extract & $45.41 \pm 0.018$ \\
Acetone extract & $8.70 \pm 0.004$ \\
Hexane extract & $0.38 \pm 0.002$ \\
\hline
\end{tabular}

Data are mean \pm SD for triplicate analysiss TOCa is Total antioxidant capacity, AAEb is ascorbic acid equivalence, $C E$ is weight of crude extract.

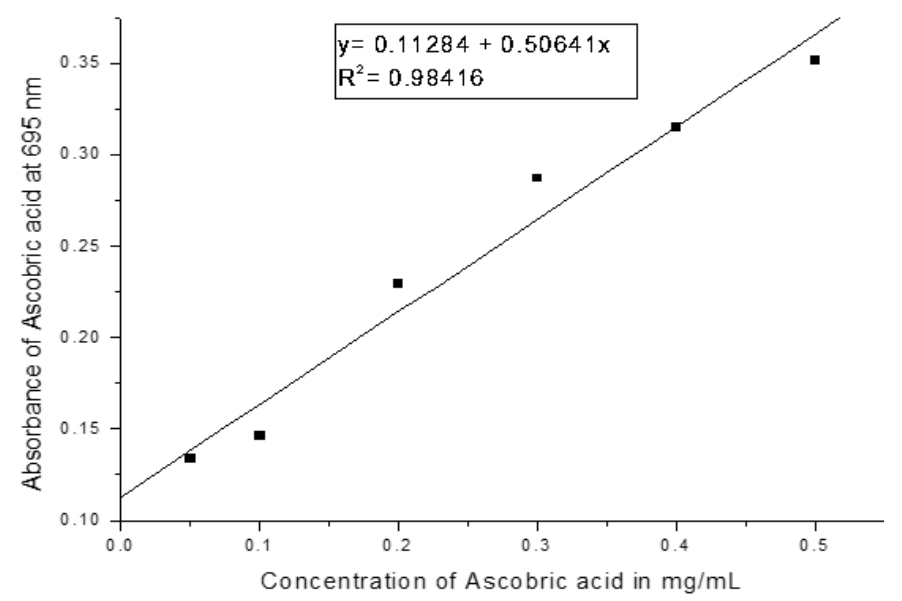

Fig. 3. Calibration curve of a series of standard solution of ascorbic acid in phosphomolmdate assay

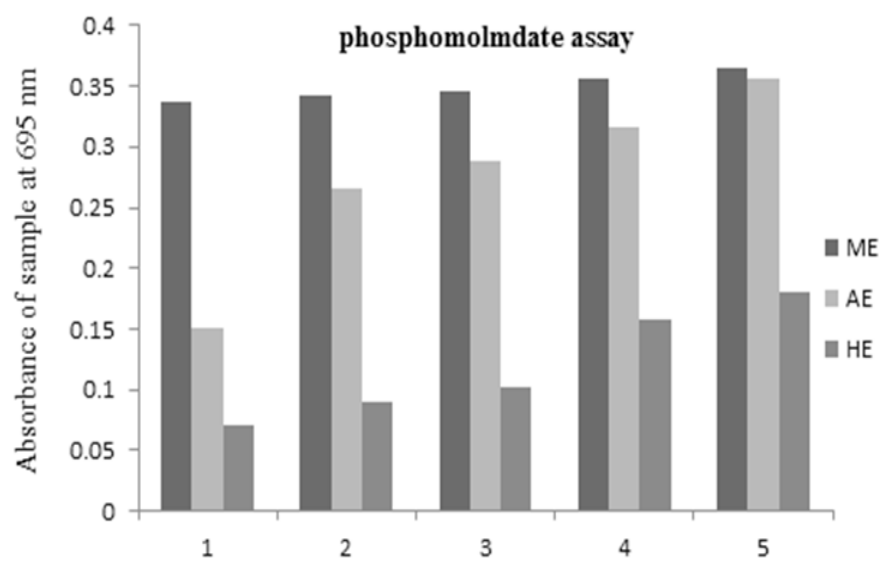

Concentration of different solvent extracts Withania somnifer a leaf in $\mathrm{mg} / \mathrm{mL}$

Fig. 4. Absorbance versus concentration of extracts in phosphomolbdate assay

\section{CONCLUSION}

This study revealed that different solvent extracts of Withania somnifera leaf is able to reduce
$\mathrm{Fe}\left[(\mathrm{CN})_{6}\right]^{3}$ to $\mathrm{Fe}\left[\left(\mathrm{CN}_{6}\right]^{2}\right.$ and reduce $\mathrm{Mo}(\mathrm{VI})$ to $\mathrm{Mo}(\mathrm{V})$ in phosphomolbdate assay. This potential reflects that the electron releasing potential of the bioactive components in the extract and it is related 
with its antioxidant activity. The reducing capacity of the test compound (extracts) showed us, its antioxidant potential.

In this study, the highest reducing power is obtained in methanolic etract of Withania somnifera leaf and the hexane extracts of Withania somnifera Leaf, however, showed lowest reducing power in FRAP assay. Therefore the Antioxidant potential of methanolic etract is higher than that of hexane extract. Antioxidant ability of Withania somnifera leaf extracts in ferric reducing power assay is found to be in order of MEWS > AEWS > HEWS. The total antioxidant capacity of Withania somnifera leaf extracts was also in the order of methanol > acetone
$>$ hexane leaf extract. Thus, in this investigation, the antioxidant potential of WS leaf may be due to the presence of polyphenolic constituent and the other phytochemicals in the leaf. Evaluation of phytochemicals contents and antioxidant potential of Withania somnifera leaf extract reveals that the leaf of Withania somnifera can be a potential candidate for an alternative medicinal uses especially with respect to its antioxidant potential. The results of the investigation infer that this plant extracts possess potent antioxidant activity and thus the anticipation of the local people in folk medicine may have a scientific basis. Therefore it is strongly recommended to isolate the antioxidant components Withania somnifera leaf extract.

\section{REFERENCES}

1. Halliwell, B. Lancet., 1994, 344, 721-724.

2. Stampfer, M. J. New Engl. J. Med., 2000, 343, 16-22.

3. Key, T. J. Lancet., 2002, 360, 861-868.

4. World Health Organization (WHO). Diet, nutrition and the prevention of chronic diseases. 2003, Technical report series 916, Geneva.

5. Alugoju, P.; Dinesh, B. Jestadi; Latha P. Ind. J. Clin.Biochem., 2015, 30(1), 11-26.

6. Yun-Zhong, F.; Sheng Y.; Guoyao, Wu., Nutrition., 2002, 18, 872- 879.

7. Valko, M.; Leibfritz D.; Moncola, J.; Cronin, MT.;Mazura, M.;Telser, J. Int. J. Biochem Cell Biol., 2007, 39(1),44-84, 12.

8. O. O., Igbinosa; I. H., Igbinosa; V. N., Chigor, Int. J. Mol. Sci., 2012, 12, 2958-2971.

9. Reuter, S.; Gupta, S.C.; Chaturvedi, M.M.; Aggarwal, B.B. Free Radical Bio. Med., 2010, 49(11), 1603-1616, ISSN: 0891-5849.

10. Bravo, L. Nutr. Rev., 1998, 56, 317-333.

11. Valkoa, M.; Leibfritz, D.; J., Moncol; T.D. Cronin; M., Mazura; J., Telser. Int. J. Biochem. Cell. B. (Elsevier)., 2007, 39, 44-84.

12. R., Ksouri; W., Megdiche; A., Debez; H., Falleh; C., Grignon; C., Abdelly, Elsevier. Plant Physiol. Biochem., 2007, 244, 249.

13. Fang, Y.Z. Free radicals and nutrition. Theory and application of free radical biology. Beijing: Scientific Press. 2002,647.

14. Salah, N.; Miller, N.J.; Paganga, G.; Tijburg, L.; Bowell, G.P.; Rice-Evans, C. Arch. Biochem Biophys.,1995, 1, 322(2), 339-46

15. Sissay, B.; Mekbib, T.; J.C. Regnier, Dharini, S. Fruits., 2009, 64, 285-294.

16. Amare G. Some common medicinal and poisonous plants used in Ethiopian folk medicine Addis Abeba University, Addis Abeba,
Ethiopia. 1976, Reference : VG 07 \& HG 07.

17. Mesfin, T.; Debella, H.; and Yehenew, G. Ethiopian Journal of Health., 2005, 15, 89-106.

18. Fassil, K.; and Getachew A. Utilization and conservation of medicinal plants in Ethiopia. Addis Ababa University Academic press, Addis Ababa.1999.

19. Getachew, A.;Dawit, A. and Kelbessa U. Ethiopian Pharmaceutical Journal., 2001, 19, 30-47.

20. Bolling, B.; Dolnikowski, G.; Blumberg, J.; Chen, C.Y. Food Chemistry., 2010, 122, 819-825.

21. Menghinello, P. Journal of liquid chromatography \& related technologies., 1999, 22(19) 3007-3018.

22. Roopalatha, U. C.; Vijay, M. Int. J. Pharm. Pharm. Sci., 2013, 5, 3.

23. Atawodi, S.E. J. Med. Food., 2010, 13(3), 710-716.

24. Umamaheswari, M.;Chatterjee, TK. Afr J Trad Compl Altern Med., 2008, 5, 61-73.

25. Bushra, S.; Farooq, A.; Muhammad, A. J. Molecules., 2009, ISSN, 1420-3049.

26. Asmare, A. and Kesara, Na-B.Ch. Afr. J. Pharm. Pharmacol., 2015, 9(25), pp. 615-627.

27. Cho, E.J.;Yokozawa, T.;Rhyu, D.Y.; Kim, S.C.; Shibahara, N.; Park, J.C. Phytomedicine., 2003, 10, 544.

28. Irshad,Md.; Zafaryab,Md.; Man Singh, M. Moshahid, A. Int. J. Med. chem., 2012, Article ID 157125, 6 pages.

29. Sayed, A.; El-toumy, S. M.; Mohamed, E.; Abdel-Tawab, H.M. Journal of American Science., 2011, 7(3).

31. Ming-Chih, S.; Cheng-Ming, C.;Sue-Ming, K.; Min-Lang, T. Int. J. Mol. Sci., 2011, 12, 6077-6088.

32. NurAlam,Md.;Nusrat, J.; Bristi, R. Saudi Pharmaceutical Journal., 2013, 21, 143-152. 